\title{
Factors affecting outcome in children with snake envenomation: a prospective observational study
}

\author{
Jhuma Sankar, Rehana Nabeel, M Jeeva Sankar, Leena Priyambada, S Mahadevan
}

Department of Paediatrics, Jawaharlal Institute of Postgraduate Medical Education and Research, Puducherry, Puducherry, India

\section{Correspondence to} Dr S Mahadevan, Department of Paediatrics, Jawaharlal Institute of Postgraduate Medical Education and Research, Puducherry, Puducherry 605006, India; smahadevan11@gmail.com

Received 14 September 2012 Revised 30 April 2013

Accepted 2 May 2013 Published Online First 28 May 2013

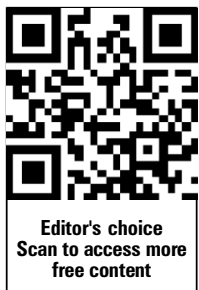

To cite: Sankar J, Nabeel R, Sankar MJ, et al. Arch Dis Child 2013;98:596-601.

\section{ABSTRACT \\ Objectives To evaluate clinical outcome and factors}

affecting outcome in children with snake envenomation.

Design Prospective observational study.

Setting Paediatric intensive care unit of a tertiary care teaching hospital in India.

Patients We prospectively enrolled children $\leq 12$ years of age admitted to our hospital with a definitive history of snake bite from August 2007 to June 2010.

Measurements and Main Results Demographic characteristics and clinical course of the enrolled children were recorded in a structured proforma and analysed using appropriate statistical methods. Children were treated as per the WHO guidelines (2005) on the management of snake bite in children. Of 110 children studied, 77 (69\%) were male. Most (72; 64.2\%) had features predominantly of haematotoxic envenomation while $20(18 \%)$ and $18(16 \%)$ children had features of neurotoxic envenomation and local involvement, respectively. 14 children (13\%) died and 13 (12\%) had major disabilities. On univariable analysis, the following prehospital and admission variables were found to be significantly associated with poor outcome: age, walking for $>1 \mathrm{~km}$ after the bite, vomiting, haemoglobin $\leq 10 \mathrm{~g} / \mathrm{dl}$ at admission and species of snake (cobra). On multivariable analysis, only younger age (adjusted OR $0.85 ; 95 \% \mathrm{Cl} 0.7$ to 0.9 ), walking for $>1 \mathrm{~km}$ after the bite (adjusted OR 57; 95\% Cl 4.2 to 782) and haemoglobin $\leq 10 \mathrm{~g} / \mathrm{dl}$ at admission (adjusted OR 6; 95\% Cl 2 to 18.2) remained significant.

Conclusions Younger age at presentation, anaemia (haemoglobin $\leq 10 \mathrm{~g} / \mathrm{dl}$ ) and distance walked after the bite may be independent predictors of mortality and morbidity in children with snake bite. These features in victims of snake bite warrant early referral to and management in tertiary care centres.

\section{INTRODUCTION}

Globally, 421000 envenomings and 20000 deaths occur each year due to snake bite. The highest burden exists in South Asia, Southeast Asia and sub-Saharan Africa where $>100000$ envenomings occur annually. ${ }^{12}$ Among the South East Asian countries, India has emerged as the country with the highest mortality. In the first ever community based survey in India, based on the verbal autopsy method, Mohapatra et $a l^{3}$ estimated that annually, 45900 deaths could be attributed to snake bites. More than $25 \%$ of these deaths occurred in children aged 5-14 years of age.

Several studies, mostly retrospective, have evaluated the demographic characteristics, clinical profile and outcome in both adults and children with snake envenomation, ${ }^{4-7}$ but few have evaluated the risk

\section{What is already known on this topic}

- Use of tourniquet and/or native treatment, delayed administration of antivenom and neurotoxicity are some of the factors affecting outcomes in adults with snake envenomation.

- Delay in institution of snake antivenom (SAV) treatment and children $<5$ years of age form a high risk group in the pediatric population.

\section{What this study adds}

- Prehospital factor, such as distance walked after the bite, is an independent predictor of mortality and morbidity in children with snake envenomation.

- Patient characteristics, such as younger age at admission and anaemia (haemoglobin $\leq 10 \mathrm{gm} /$ $\mathrm{dL}$ ), may be important in determining outcome in children with snake envenomation.

factors associated with mortality and morbidity. ${ }^{8-10}$ We therefore undertook this study with the objective of determining the outcomes and risk factors associated with poor outcome in children with snake envenomation. Such information could help in identifying children who need urgent referral from the primary care level. It would also help in deciding the extent of support required in children admitted with snake envenomation in referral centres.

\section{METHODS}

\section{Design and study population}

We enrolled patients prospectively over a 3 year period from August 2007 to June 2010. We had to stop enrolment of patients after 3 years as an interventional study was started after this period which could have affected our study results. We included all children aged $\leq 12$ years of age, with a definite history of snake bite attending the outpatient or emergency services of our hospital, a tertiary care institution in South India. We excluded children with chronic illnesses (eg, chronic kidney disease or congenital heart disease) and also those with unknown bites. Unknown bites were defined as bites in which the victims or their family members were sure it was not by a snake but something else.

Outcome variables and their measurement The primary outcome variables were: (a) the incidence of poor outcome, defined as death or major disability such as the need for amputation and/or 
skin graft; and (b) risk factors at admission associated with such outcomes.

The factors which we wanted to evaluate in our study included prehospital factors such as use of native treatment, tourniquet, bite to hospital arrival time and distance walked. The study definitions are provided in box 1. ${ }^{11-15}$ We chose a walking distance of $>1 \mathrm{~km}$ as a cut-off as it was more accurate for the parents to recollect the distance walked in kilometres. Assuming the average distance covered while walking is $6 \mathrm{~km} / \mathrm{h}$, we used a cut-off of $1 \mathrm{~km}$ to define the distance walked as it would amount to a duration walked of $10 \mathrm{~min}$ or more. The scientific basis for this distance walked stems from a previously reported simulated human study mimicking snake/spider venom in which it was found that despite the use of first aid measures, circulation of the radiotracer was inevitable in subjects who walked for more than $10 \mathrm{~min}^{16}$ In India, snake bite is a common problem in rural areas where most people are illiterate. When asked about the duration of walking after the bite, parents would often not be able to estimate this. They would instead recollect the kilometres walked as there are kilometre markings all along the roadways. Therefore, we could only record the kilometres walked in these patients. Also, we observed that parents would easily recollect if it was more than $1 \mathrm{~km}$ when enquired. However, if the distance walked was $>1 \mathrm{~km}$, they were not sure about the metres walked. Therefore, to make the data more objective, we chose a cut-off of $1 \mathrm{~km}$.

Factors at admission which we wanted to evaluate included demographic features such as age, gender, presence of severe malnutrition, ${ }^{17}$ clinical presentation (ie, vomiting), type of envenomation, ${ }^{11}$ species of snake and abnormal laboratory investigations, such as an abnormal 20 min whole blood clotting time (WBCT) test at admission, presence of moderate to severe anaemia (defined as haemoglobin levels $\leq 10 \mathrm{gm} / \mathrm{dl})^{18}$ and elevated serum creatinine, as we thought they were clinically important.

We followed-up all the patients until hospital discharge or death, whichever came first. We prospectively collected the baseline characteristics, including age, gender, prehospital factors such as use of tourniquet and/or native treatment, course in hospital, including investigations such as the $20 \mathrm{~min}$ WBCT test, details of snake antivenom (SAV) administration and clinical outcome of all of the children enrolled in the study. Details of treatment received in the primary health care centres were also collected from referral slips. For determining risk factors, we compared the predefined factors (mentioned above) of children who died or had major disabilities with those who were discharged without any disability.

\section{Management of enrolled children}

We followed a uniform protocol for management of children with snake envenomation throughout the study period, as per the WHO guidelines for management of snake bites in the South East Asian region (2005). ${ }^{11}$ Accordingly, the diagnosis of snake envenomation was based on one or more of the following features: history of snake bite, presence of fang marks, presence of local manifestations, such as pain and swelling at the site of the bite, or systemic manifestations, such as spontaneous bleeding or features of neurotoxicity and/or if the dead snake was brought in for identification.

Children were managed with intravenous fluids, inotropes, antibiotics and blood products, with mechanical ventilation and dialysis when necessary. Definitive therapy in the form of polyvalent SAV serum (Serum Institute of India, Pune), which contains antisera against Naja naja, Bungarus caerulus, Vipera russeli and Echis carinatus, was administered as per the WHO guidelines. ${ }^{11}$ The

\section{Box 1 Definitions used in the study}

- Native treatment: any type of native treatment, such as incision of the wound, lime application, powder application, etc.

- Immobilisation: status: if any type of crepe bandage were applied as per the pressure immobilisation method or if the limb was splinted and the patient carried in a stretcher to the hospital. ${ }^{11}$

- Bite to antivenom time: time taken to starting snake antivenom (SAV) therapy.

- Bleeding manifestations (local): oozing, ecchymosis at the site of the bite. ${ }^{11}$

- Bleeding manifestations (systemic): haematuria, haematemesis, melaena, pulmonary bleed, intracranial bleed, intraperitoneal bleed. ${ }^{11}$

- Adverse events during SAV administration: urticaria, itching, fever, chills, nausea, vomiting, diarrhoea, abdominal cramps, tachycardia, hypotension, bronchospasm and/or angio-oedema. ${ }^{11}$

- Compartment syndrome: defined as the compression of nerves, blood vessels and muscle inside a compartment (connective tissue) within the body resulting in loss of limb or life if left untreated. ${ }^{12}$

- Respiratory failure: defined as any process leading to inadequate oxygenation $\left(\mathrm{PaO}_{2}<60 \mathrm{~mm} \mathrm{Hg}\right.$ with an $\mathrm{FiO}_{2}$ $>0.6$ ) or ventilation (acute $\mathrm{PacO}_{2}>50 \mathrm{~mm} \mathrm{Hg}$ ). ${ }^{13}$

- Requirement of mechanical ventilation: need for mechanical ventilation in the presence of abnormal arterial blood gas and/or evidence of neuromuscular weakness involving the respiratory muscles or haemodynamic instability. ${ }^{13}$

- Acute kidney injury: an abrupt (within 48 h) reduction in kidney function defined as an absolute increase in serum creatinine of $\geq 0.3 \mathrm{mg} / \mathrm{dl}$, an increase in serum creatinine of $\geq 1.5$-fold from baseline or reduction in urine output (oliguria $<0.5 \mathrm{ml} / \mathrm{kg} / \mathrm{h}$ for $>6 \mathrm{~h}$ )..$^{14}$

- Requirement for dialysis: need for dialysis in the presence of stage 3 or more of acute kidney injury. ${ }^{14}$

- Shock: defined as a clinical state characterised by inadequate tissue perfusion resulting from delivery of oxygen and metabolic substrates that is insufficient to meet metabolic demands and objectively assessed as tachycardia, tachypnoea, normal/low blood pressure $(<5$ th centile for age) (compensated/uncompensated), prolonged capillary refill of $>2 \mathrm{~s}$ (cold shock) or flash capillary refill (warm shock), diminished (cold shock) or bounding (warm shock) peripheral pulses, mottled cool extremities (cold shock), decreased urine output of $<1 \mathrm{ml} / \mathrm{kg} / \mathrm{h}$ and/or alteration of mental status (adapted from the clinical definition of septic shock-Zimmerman: shock states). ${ }^{15}$

- Severe malnutrition: weight for age $<50 \%$ as per Indian Academy of Paediatrics classification for malnutrition in children. ${ }^{16}$

initial dose of SAV administered was 8-10 vials for haematotoxic and neurotoxic bites as well as in children with extensive local involvement (eg, swelling involving half the bitten limb or rapidly crossing a joint in the absence of a tourniquet). During SAV infusion, children were continuously monitored for any adverse reactions. In the case of a reaction (box 1), the infusion was stopped 
and the patient was administered intramuscular epinephrine, chlorpheniramine and hydrocortisone. SAV was restarted once the allergic symptoms abated. Subsequent doses of SAV in haematotoxic bites were administered based on the 20 min WBCT test result which was performed every $6 \mathrm{~h}$. In cases of neurotoxic bites, further doses were repeated based on progression of symptoms such as ophthalmoplegia, respiratory paralysis and/or quadriparesis after $1-2 \mathrm{~h}$ of the initial dose. The atropine neostigmine test was performed in all cases of suspected neurotoxic bites. Those children who responded to this test were given repeat doses until their symptoms improved completely.

\section{Statistical analysis}

Data of all the enrolled children were collected on a standard proforma and entered into Microsoft Excel 2007. Statistical analysis was performed using Stata V.11.2 (StataCorp, College Station, Texas, USA). The $\chi^{2}$ test was used to compare categorical variables while the Student's t test or Wilcoxon rank sum test was used for continuous variables. A p value of 0.05 was considered significant.

For determining risk factors, we performed univariable logistic regression analysis followed by multivariable logistic regression with the backward stepwise elimination variable selection method using death or disability as the dependent variable and all others as independent variables. The results of the multivariable analysis are reported as adjusted OR with 95\% CI.

As our primary objective was to identify risk factors associated with poor outcomes, we did not use any formal statistical methods to calculate sample size. The sample was defined in terms of number of cases recruited during the 3 year study period.

\section{RESULTS}

\section{Demographic details}

A total of 122 children presented with a definite history of snake bite during the study period. Of these, 12 children had to be excluded as per prespecified exclusion criteria (figure 1). Thus a total of 110 children, 76 (69\%) of whom were males, participated in the study. Most of the bites occurred during the night $(66 ; 60 \%)$. Species identification was possible in only 81 cases. In the remaining cases the victims or their parents confirmed that it was a snake but could not identify the snake. Of the 81 snakes identified, 44 were saw scaled viper, 16 were Russell's viper, 11 were krait and 10 were cobras.

Thirty-seven children (34\%) received native treatment in the form of cuttings, application of lime, etc. None had the local site/limb immobilised by pressure immobilisation bandage before admission. Sixty children (54\%) had a tourniquet applied at the site of the bite. Only seven (6\%) children walked for a distance of $>1 \mathrm{~km}$ prior to reaching the hospital. Most of the children $(n=62$, $56 \%$ ) reached the hospital within $6 \mathrm{~h}$ of the bite. The median Paediatric Index of Mortality Score of the study population was $-1.48(-2.2,-0.8)$ (table 1$)$.

\section{Investigations}

The 20 min WBCT test was abnormal at admission as well as after $24 \mathrm{~h}$ in $12(11 \%)$ children. All of these children showed evidence of disseminated intravascular coagulation in the form of increased D-dimers and thrombocytopenia.

\section{SAV administration}

SAV was administered to 106 children (96\%). Only four children with exclusive local symptoms did not receive SAV. Children with neurotoxic bites and those with evidence of coagulopathy after $24 \mathrm{~h}$ required more SAV. All children visiting the primary health care centre before admission had received SAV. However, the median number of vials used was less than the recommended vials in two-thirds of cases $(2.5(0,5))$. Forty-four children $(40 \%)$ had allergic reactions to SAV, the most common being vomiting, chills and rigours, and hypotension.

\section{Complications and supportive treatment}

The most common complications noted were respiratory failure $(35 ; 32 \%)$ and acute kidney injury $(25 ; 23 \%)$. Mechanical ventilation and dialysis were required in 35 and 21 children, respectively. The predominant indication for ventilation was respiratory paralysis in neurotoxic victims $(n=15)$ and shock with or without pulmonary oedema in those with haematotoxic envenomation $(n=20)$. Packed red blood cells were administered to $21(19 \%)$ and fresh frozen plasma to $12(11 \%)$ children.

\section{Outcome}

Of the 110 children, 14 (13\%) died while 13 (12\%) survivors had major disabilities. The incidence of 'poor outcome' was $24.5 \%$ (95\% CI 17.2 to 33 ). Of the 14 children who died, nine had features of haematotoxic envenomation and died of either refractory shock or massive pulmonary haemorrhage. Five children with neurotoxic envenomation died due to refractory tachyarrhythmia or raised intracranial pressure. Eight children with cobra bite had major disabilities in the form of amputation of toes $(n=5)$ or fingers $(n=2)$ on the
Figure 1 Study flow chart. ICU, intensive care unit.
Children admitted to the ICU with snake bite $(n=122)$

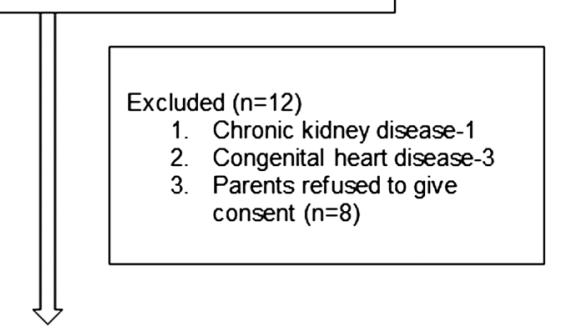


Table 1 Baseline characteristics, laboratory features, treatment and outcome of children with snake bite

\begin{tabular}{|c|c|}
\hline Variable & $\begin{array}{l}\text { All patients } \\
(n=110)\end{array}$ \\
\hline Age (years) (median, IQR) & $7(4,11)$ \\
\hline Male gender & $76(69)$ \\
\hline Severe malnutrition & $28(26)$ \\
\hline Time of bite (night) & $66(60)$ \\
\hline \multicolumn{2}{|l|}{ Prehospital treatment } \\
\hline Use of local treatment & $37(34)$ \\
\hline Use of tourniquet & $60(54)$ \\
\hline $\begin{array}{l}\text { Received treatment in the primary care facility } \\
\text { before referral }\end{array}$ & $68(61)$ \\
\hline PIM score (median, IQR) & $-1.48(-2.2,-0.8)$ \\
\hline \multicolumn{2}{|l|}{ Signs and symptoms at admission } \\
\hline Vomiting & $73(65)$ \\
\hline Local swelling & $63(57)$ \\
\hline Shock & $24(22)$ \\
\hline Acute kidney injury & $37(34)$ \\
\hline \multicolumn{2}{|l|}{ Type of envenomation* } \\
\hline Predominantly haematotoxic & $72(64)$ \\
\hline Predominantly neurotoxic & $20(18)$ \\
\hline Predominantly local & $18(16)$ \\
\hline \multicolumn{2}{|l|}{ Snake species } \\
\hline Vipera russeli & $16(15)$ \\
\hline Echis carinatus & $42(38)$ \\
\hline Bungarus caerulus & $11(10)$ \\
\hline Naja naja & $10(9)$ \\
\hline Unidentified & $29(26)$ \\
\hline \multicolumn{2}{|l|}{ Investigations } \\
\hline Abnormal 20 min WBCT test at admission & $61(55)$ \\
\hline Admission $\mathrm{Hb}$ (mean, SD) & $9.7(2.3)$ \\
\hline Creatinine (mg/dl) (median, IQR) & $0.6(0.5,0.6)$ \\
\hline Bite to SAV administration time (h) (median, IQR) & $5(3,8)$ \\
\hline Dose of SAV administered (vials) (median, IQR) & $15(10,19)$ \\
\hline Haematotoxic (median, IQR) & $15(10,18)$ \\
\hline Neurotoxic (median, IQR) & $18(15,22)$ \\
\hline Local symptoms (median, IQR) & $15(8,16)$ \\
\hline SAV reaction & $44(40)$ \\
\hline Hypotension & $9(8)$ \\
\hline \multicolumn{2}{|l|}{ Outcome } \\
\hline Discharge & $83(75)$ \\
\hline Died & $14(13)$ \\
\hline Disability & $13(12)$ \\
\hline
\end{tabular}

bitten extremity and necrosis of skin and soft tissues $(n=1)$ requiring skin graft. Five children with Russell's viper bite also required skin graft.

\section{Risk factors of poor outcome}

On univariable analysis, the following variables were found to be significantly associated with death or major disability: age, walking for $>1 \mathrm{~km}$ after the bite, vomiting, haemoglobin $\leq 10 \mathrm{gm} / \mathrm{dl}$ at admission and species of snake (cobra) (table 2).

On stepwise logistic regression of all variables included in the univariable analysis, we found only younger age (adjusted OR 0.85 ; $95 \%$ CI 0.7 to 0.9 ), walking for $>1 \mathrm{~km}$ after the bite (adjusted OR 57; 95\% CI 4.2 to 782) and haemoglobin $\leq 10 \mathrm{~g} / \mathrm{dl}$ at admission (adjusted OR 6.2; 95\% CI 2 to 18.2) to be independent risk factors associated with death or disability (table 3).

\section{DISCUSSION}

Few studies have prospectively evaluated the risk factors associated with poor outcome in adults with snake envenomation. ${ }^{9} 16$ Only one retrospective paediatric study in the English literature has evaluated the outcome and risk factors for serious complications and/or mortality in children with snake envenomation. ${ }^{17}$ The authors observed that delay in institution of SAV treatment and children $<5$ years of age formed a high risk group. Ours is therefore the first prospective study to examine the risk factors associated with increased mortality and morbidity in children with snake envenomation.

The clinical profile of the enrolled children, including the type of envenomation, clinical features and laboratory abnormalities, was similar to previously reported studies in children from India. ${ }^{6} 18$

The mortality rate in our study (13\%) was higher than previously reported in hospital based studies involving children $(3-7.7 \%) .^{6} 17$ We presume the differences in severity of envenomation and the availability of resources to be the possible reasons for the higher mortality rate observed in our study. Being a referral hospital, children with severe envenomation are more likely to be referred to our centre from a primary care facility. Thirteen children in our study had major morbidities, such as skin necrosis requiring grafting and/or amputation of fingers or toes of the bitten extremity.

On analysing the determinants of poor outcome, we found prehospital factors, such as the distance walked, to be significantly associated with death or severe disability. The WHO guideline recommends immobilisation of the bitten part during transport as any movement may cause release of venom into the circulation and increase systemic toxicity (level of recommendation E). ${ }^{11}$ This recommendation is based on findings of a single study of 24 cases of simulated snake/spider bite by Howarth et al. $^{16}$ The primary objective of their study was to evaluate the normal lymphatic transit times by lymphoscintigraphy and evaluate the efficacy of first aid measures, such as bandages and splints, on these transit times. The authors observed that the mean periphery to systemic circulation time was $58( \pm 7) \mathrm{min}$ after injection. First aid was effective at particular bandage pressures in the upper and lower limbs. However, the interesting finding was that, despite appropriate first aid measures, lymphatic flow of the radiotracer (simulated snake antigen) in both the lower and upper limbs was seen in all subjects who walked for $10 \mathrm{~min}$ or more. No further studies have validated this finding in adults. Thus, ours is the first study to address this important factor and its effect in children with snake envenomation. Future studies from countries with high literacy rates could focus on the exact duration walked after a bite, or the exact distance walked that may be associated with poor outcome.

Similar to previous studies of the effect of prehospital factors ${ }^{10}$ in victims of snake envenomation, we found that use of a tourniquet and native treatment was higher among those with a poor outcome although this did not reach statistical significance. Children with extensive local involvement (due to a cobra bite) were found to have higher morbidity at discharge from hospital. However, this factor became insignificant on multivariable analysis. It is well known that cobra bite is associated with extensive tissue necrosis. ${ }^{11} 12$ Therefore, it was not surprising to find that those bitten by a cobra have a poor outcome in 
Table 2 Univariable logistic regression of factors affecting outcome in children with systemic envenomation

\begin{tabular}{|c|c|c|c|c|}
\hline \multirow{2}{*}{ Variable } & \multirow[b]{2}{*}{ Died/major disability $(n=27)$} & \multirow[b]{2}{*}{ Discharged $(n=83)$} & \multicolumn{2}{|l|}{ Unadjusted OR } \\
\hline & & & $(95 \% \mathrm{Cl})$ & p Value \\
\hline Age (years) (median, IQR) & $5(3,11)$ & $8(5,12)$ & - & 0.03 \\
\hline Age $\leq 6$ years & $16(59)$ & $27(32)$ & 1.82 (1.17 to 2.83$)$ & 0.01 \\
\hline Severe malnutrition & $9(33)$ & $19(23)$ & $1.7(0.64$ to 4.2$)$ & 0.3 \\
\hline Male gender & $18(67)$ & $58(70)$ & 0.95 (0.7 to 1.29 ) & 0.7 \\
\hline Tourniquet use & $19(70.4)$ & $41(49.4)$ & $1.43(1.03$ to 1.97$)$ & 0.056 \\
\hline Native treatment & $11(41)$ & $26(31)$ & $1.30(0.75$ to 2.26$)$ & 0.36 \\
\hline Walking for $>1 \mathrm{~km}$ after bite & $6(22)$ & $1(1.2)$ & $18.4(2.32$ to 146.4$)$ & 0.001 \\
\hline Bite to SAV administration time (h) (median, IQR) & $6(4,12)$ & $5(2,8)$ & - & 0.11 \\
\hline Bite to $\mathrm{SAV}$ administration $>6 \mathrm{~h}$ & $10(37)$ & $39(47)$ & 0.78 (0.45 to 1.3$)$ & 0.37 \\
\hline Vomiting & $23(85.2)$ & $50(60)$ & $1.41(1.12$ to 1.79$)$ & 0.02 \\
\hline Abnormal 20 min WBCT test & $10(37)$ & $51(61)$ & $0.75(0.48$ to 1.19$)$ & 0.8 \\
\hline Creatinine (mg/dl) (median, IQR) & $0.5(0.5,0.6)$ & $0.6(0.5,0.6)$ & - & 0.11 \\
\hline Creatinine $\geq 0.6 \mathrm{mg} / \mathrm{dl}$ & $17(63)$ & $47(56)$ & 1.11 (0.79 to 1.57 ) & 0.56 \\
\hline PIM score (median, IQR) & $-1.55(-2.24,-0.55)$ & $-1.3(-2.18,-0.84)$ & - & 0.72 \\
\hline Admission $\mathrm{Hb} \leq 10 \mathrm{~g} / \mathrm{dl}$ & $20(74)$ & $17(20.7)$ & 3.62 (2.24 to 5.84$)$ & $<0.001$ \\
\hline \multicolumn{5}{|l|}{ Type of envenomation* $†$} \\
\hline Haematotoxic & $14(52)$ & $58(70)$ & $0.3(0.1$ to 0.9$)$ & 0.03 \\
\hline Neurotoxic & $5(19)$ & $15(18)$ & 0.41 (0.1 to 1.6$)$ & 0.21 \\
\hline Local manifestations & $8(30)$ & $10(12)$ & - & - \\
\hline \multicolumn{5}{|l|}{ Snake speciest } \\
\hline Vipera russeli & $5(19)$ & $11(13)$ & - & - \\
\hline Echis carinatus & $6(22)$ & $38(46)$ & 0.34 (0.08 to 1.4 ) & 0.13 \\
\hline Bungarus caerulus & $3(11)$ & $8(10)$ & 0.82 (0.15 to 4.5 ) & 0.82 \\
\hline Naja naja & $8(30)$ & $2(2)$ & 8.7 (1.3 to 57$)$ & 0.02 \\
\hline Unidentified & $5(19)$ & $24(29)$ & $0.45(0.1$ to 1.9$)$ & 0.28 \\
\hline
\end{tabular}

Data are expressed as number (\%) unless otherwise indicated.

*Predominant manifestation at presentation.

TThe OR calculated for the group is in comparison with the first variable that is local manifestations in the case of type of envenomation and Vipera russeli in the case of snake species $\mathrm{Hb}$, haemoglobin; PIM, Paediatric Index of Mortality; SAV, snake antivenom; WBCT, whole blood clotting time.

terms of disabilities, such as amputation or requirement for skin graft.

Several patient related factors, such as younger age, vomiting, increased serum creatinine, abnormal $20 \mathrm{~min}$ WBCT test, neurotoxic envenomation and increased severity of illness at admission, ${ }^{7-9} 19$ have been found to be associated with increased mortality and morbidity in victims of snake envenomation. Likewise, in our study, we found younger age, vomiting and haemoglobin $\leq 10 \mathrm{gm} / \mathrm{dl}$ at admission to be associated with poor outcome. However, on multivariable analysis, only younger age and admission haemoglobin $\leq 10 \mathrm{gm} / \mathrm{dl}$ remained significant.

Similar to previously reported studies from the West, we found that the risk of poor outcome increased with decreasing age. The risk increased by $17 \%$ with each declining year. In a large epidemiological study from California ${ }^{20}$ in which the authors tried to analyse human deaths attributable to venomous animals in California from 1960 to 1976, the authors observed that almost half of the deaths from venomous snake bites occurred in children younger than 5 years of age. The authors reasoned that children appeared to be particularly vulnerable to snake bites not only because of their small size and curiosity but also because most young children were unable to recognise venomous snakes or to give them the respect they deserve. In another study on poisonous snake bites in central Texas, ${ }^{21}$ the authors observed that of the 23 patients (of a total of 67 patients) receiving antivenom therapy, 50\% were children younger than 12 years of age. Possibly, younger children, owing to their large body surface area, less protein to bind the circulating venom and smaller extracellular fluid volume, are particularly susceptible to severe envenomation and mortality. ${ }^{22}$ Reportedly, some snakes have the ability to identify a small thermal target and can deliver a more accurate venom dosage. The large thermal size of an adult seems to confuse the snake, resulting in unpredictable venom delivery. ${ }^{22}$ Thus it seems that the hypothesis generated from the above epidemiological studies

Table 3 Multivariable logistic regression of factors affecting outcome in children with snake envenomation

\begin{tabular}{|c|c|c|c|c|}
\hline Variable & Died/major disability $(n=27)$ & Discharged $(n=83)$ & Adjusted OR (95\% Cl) & $\mathrm{p}$ Value \\
\hline Age (years) (median, IQR) & $5(3,11)$ & $8(5,12)$ & $0.85(0.7,0.90)$ & 0.04 \\
\hline Distance walked >1 km & $6(22)$ & $1(1.2)$ & $57(4.2,782)$ & 0.002 \\
\hline Anaemia at admission $(\mathrm{Hb} \leq 10 \mathrm{~g} / \mathrm{dl})$ & $20(74)$ & $17(20.7)$ & $6.2(2,18.2)$ & 0.001 \\
\hline
\end{tabular}

\footnotetext{
$\mathrm{Hb}$, haemoglobin.
} 
is confirmed through the findings in our study and younger children should be preferably referred to tertiary centres owing to their increased susceptibility to the venom and its after effects.

Among the other patient related factors, we found haemoglobin levels $\leq 10 \mathrm{gm} / \mathrm{dl}$ at admission to be an independent predictor of poor outcome in these children. Our study is the first to report this association. We presume that this factor has manifested itself in our study as the study population was children from India where the prevalence of anaemia in the under $5 \mathrm{~s}$ is $70 \%$ and increases to almost $80 \%$ in children $<3$ years of age. ${ }^{23}$ The most common cause of anaemia in our country is malnutrition (especially iron deficiency) owing to the scarcity of food and/or insufficient intake compared with need, especially during the rapid growth stages of infancy and early childhood. However, the prevalence of severe malnutrition was similar in both groups and did not seem to affect clinical outcome. Thus it appears that, low admission haemoglobin seems to have an independent effect on mortality and morbidity in these patients. The possible explanations for this independent effect of anaemia could be: (a) iron deficiency anaemia may result in reduced immunity which makes them more prone to infections (secondary infections in cases of snake bite); and (b) in victims of snake bite, intravascular haemolysis and bleeding (especially in cases of haematotoxic envenomation) may aggravate iron deficiency anaemia by further lowering haemoglobin levels. ${ }^{22}$ Low haemoglobin levels increase the morbidities in victims with shock by further compromising the oxygen carrying capacity. To summarise, moderate to severe anaemia at admission in a victim of snake envenomation may aggravate the disease and lead to poor outcome. Treating a haemoglobin level of $\leq 10 \mathrm{gm} / \mathrm{dl}$ by packed cell transfusion and close monitoring of serial haemoglobin levels may help improve clinical outcome in victims of snake envenomation. Therefore, such victims need to be transferred to centres where such facilities are available.

The strength of our study is that it is the first prospective study to evaluate factors at admission associated with poor outcome in children with snake envenomation. However, one major limitation of our study was the small sample size that may not have been sufficient to evaluate the association between all of the risk factors and poor outcome. This could have led to an overestimation of the likely number of significant factors. Only a multicentre study with about 1000 children would help in correctly identifying the risk factors. The other important limitation was that, for logistical reasons, we did not perform enzyme immunoassay to identify the snake species or estimate venom levels in blood. Such estimation would have helped in confirming the biting species and served as a guide to administration of SAV.

In conclusion, 10 lack of immobilisation, anaemia at admission (haemoglobin $\leq 10 \mathrm{gm} / \mathrm{dl}$ ) and younger age may be independent predictors of poor outcome in victims of snake envenomation. These features in victims of snake bite warrant early referral to and management in tertiary care centres.

Acknowledgements The valuable interactions and periodic advice from lan D Simpson and Ingrid Jacobsen of the Indian Snakebite Research Initiative (indiansri@gmail.com) are gratefully acknowledged. We are also thankful to Miss Kalaivani M, PhD, AllMS, for her valuable input into the statistical analysis.

Contributors JS was involved in the study design, protocol and statistical analysis, and wrote the paper. RN was involved in the study protocol, collected the data and helped in the writing of the paper. MJS was involved in the study design, statistical analysis and revising the manuscript for critical content. LP was involved in the study protocol and statistical analysis. All authors were involved in data interpretation. All authors revised the manuscript and read and approved the final version. SM conceived and designed the study protocol, supervised data entry and is the guarantor of the paper.

Patient consent Obtained from the parents.

\section{Competing interests None.}

Ethics approval The study was approved by the Jawaharlal Institute of Post Graduate Medical Education and Research, Puducherry.

Provenance and peer review Not commissioned; externally peer reviewed.

\section{REFERENCES}

1 Kasturiratne A, Wickremasinghe AR, de Silva N. The global burden of snakebite: a literature analysis and modelling based on regional estimates of envenoming and deaths. PLoS Med 2008;5:e218.

2 WHO. Snakebite. http://www.who.int/neglected_diseases/diseases/snakebites/en/ index.html (accessed 30 May 2012).

3 Mohapatra B, Warrell DA, Suraweera W, et al. Million Death Study Collaborators. Snakebite mortality in India: a nationally representative mortality survey. PLoS Negl Trop Dis 2011;5:e1018.

4 Nisar A, Rizvi F, Afzal M, et al. Presentation and complications of snakebite in a tertiary care hospital. J Coll Physicians Surg Pak 2009;19:304-7.

5 Kulkarni ML, Anees S. Snake venom poisoning: experience with 633 cases. Indian Pediatr 1994;31:1239-43.

6 Lahori UC, Sharma DB, Gupta KB, et al. Snake bite poisoning in children. Indian Pediatr 1981;18:193-7.

7 Ozay G, Bosnak M, Ece A, et al. Clinical characteristics of children with snakebite poisoning and management of complications in the pediatric intensive care unit. Pediatr Int 2005;47:669-75.

8 Kalantri S, Singh A, Joshi R, et al. Clinical predictors of in-hospital mortality in patients with snake bite: a retrospective study from a rural hospital in central India. Trop Med Int Health 2006;11:22-30.

9 Suchithra N, Papachan JM, Sujathan P. Snake envenoming in Kerala, South India: clinical profile and factors involved in adverse outcomes. Emerg Med J 2008:25:200-4

10 Michael JC, Sharma SK, Chappuis F, et al. Impact of snake bites and determinants of fatal outcomes in southeastern Nepal. Am J Trop Med Hyg 2004;71:234-8.

11 Warrell DA. WHO/SEARO Guidelines for the clinical management of snake bites in the Southeast Asian region. http://www.searo.who.int/linkfiles/bct_snake_bite_guidelines. pdf (accessed 30 May 2012)

12 Twaddle BC, Amendola A. Compartment syndrome. In: Browner BD, Jupiter JB, Levine AM, et al, eds. Skeletal trauma, 4th edn. Philadelphia, PA: Saunders Elsevier, 2009:chap 13 341-66.

13 Venkataraman TS. Mechanical ventilation and respiratory care. In: Fuhrman BP, Zimmerman JJ Pediatric critical care, 3rd edn. Philadelphia: Mosby Elsevier, 2005:683-718.

14 Mehta RL, Kellum JA, Shah SV, et al. Acute Kidney Injury Network: report of an initiative to improve outcomes in acute kidney injury. Crit Care 2007;11:R31.

15 Smith L, Hernan L. Shock states. In: Fuhrman BP, Zimmerman JJ, eds. Pediatric critical care, 3rd edn. Philadelphia: Mosby Elsevier, 2005:394-410.

16 Howarth DM, Southee AE, Whyte IM. Lymphatic flow rates and first-aid in simulated peripheral snake or spider envenomation. Med J Aust 1994;161:695-700.

17 Tripathi MS, Sharma V. Assessment of nutritional status of pre-schoolers in slum areas of Udaipur City. Indian J Public Health 2006;50:33-4.

18 WHO/UNICEF/UNU. Iron-deficiency anemia: assessment, prevention and control: a guide for program managers. Geneva: World Health Organization, 2001. http:// www.who.int/nutrition/publications/en/ida_assessment_prevention_control.pdf (accessed Mar 2013).

19 Michael JC, Thacher TD, Shehu MIL. The effect of pre-hospital care for venomous snake bite on outcome in Nigeria. Trans R Soc Trop Med Hyg 2011;105:95-101.

20 Ennik F. Deaths from bites and stings of venomous animals. West J Med 1980;133:463-8

21 White RR IV, Weber RA. Poisonous snakebite in central Texas. Possible indicators for antivenin treatment. Ann Surg 1991;213:466-71.

22 Aggarwal R, Thavaraj V. Snake envenomation. Indian Pediatr 1994;31:1309-13.

23 Kotecha PV. Nutritional anemia in young children with focus on Asia and India. Indian J Community Med 2011;36:8-16. 